\title{
Biyokütle kaynaklarının proximate bileşimleri ile üst ISı değerleri arasında yeni bir denklem geliştirilmesi ve denklemin başarısının araştıııması
}

\author{
Developing a new equation between proximate contents and upper heat values of biomass sources and investigating \\ the success of the equation
}

Şeyda TAŞAR

Fırat Üniversitesi, Mühendislik Fakültesi, Kimya Mühendisliği Bölümü, ELAZıĞ

Eser Bilgisi / Article Info

Araştırma makalesi / Research article

DOI: $10.17474 /$ artvinofd. 744752

Sorumlu yazar / Corresponding author Şeyda TAŞAR

e-mail: sydtasar@firat.edu.tr

Geliş tarihi / Received

29.05.2020

Düzeltme tarihi / Received in revised form

06.12.2020

Kabul Tarihi / Accepted

30.12.2020

Elektronik erişim / Online available

12.05.2021

Anahtar kelimeler:

Biyokütle

Proximate analiz

Kalorifik değer

Model eşitlik

Keywords:

Biomass

Proximate analysis

Calorific value

Model equation

\begin{abstract}
Özet
Bu çalışmada, biyokütle kaynaklarının üst ISı değerlerinin (ÜID) tahmini için proximate analizlerine dayanan yeni bir denklem geliştirilmiştir. Bu amaçla, termal dönüşüm süreçlerinde hammadde olarak kullanılabilecek biyokütle kaynaklarını temsilen on farklı biyokütle örneği seçilmiştir. Bu örneklerin kalori tayinler ve proximate analizleri yapılmış ve bir denklem geliştirilmiştir. Geliştirilen denklem kullanılarak biyokütle kaynaklarının hesaplanan ÜID değerleri ve deneysel ÜID değerleri karşılaştırılmıştır. Ayrıca mutlak sapma ve yüzde hata değerleri hesaplanmıştır. Daha sonra, biyokütle kaynaklarının proximate analiz verileri ile kalorifik değerleri arasında bir ilişki kurulmaya çalışılmıştır. MATLAB 2019A programı ile elde edilen denkleminin başarısı, literatürde bulunan 17 farklı denklemlerle kıyaslanmıştır. Geliştirilen denklemin başarısının diğer eşitliklerden yüksek olduğu, regresyon katsayısının 1 ve mutlak sapma değerlerinin sıfır olduğu belirlenmiştir. Ayrıca, geliştirilen denklemin literatürdeki farklı biyokütle örneklerinin kalorifik değerlerinin tahminindeki başarısı da araştırılmıştır. Bu aşamada da 18 farklı biyokütle kaynağı kullanılmıştır ve denklemin mutlak sapma, yüzde hata ve regresyon katsayıları tespit edilmiş̧ir. Bu değerler sırasıyla $0.91 \mathrm{~kJ} / \mathrm{g}$ (max.), \% 4.3 (max.) ve 0.91 olarak belirlenmiştir. Geliştirilen denkleminin diğer biyokütle kaynakları içinde oldukça başarılı sonuçlar verdiği sonucuna varılmıştır.
\end{abstract}

\begin{abstract}
In this study, a new equation was developed based on proximate analysis for estimation of higher heat values (HHV) of biomass sources. For this purpose, ten different biomass samples that can represent biomass resources that can be used as raw materials in thermal conversion processes have been selected and characterized. Then, a relationship was tried to be established between proximate analysis data of biomass sources and calorific values. For this purpose, data analysis was done with MATLAB 2019A program and an equation was developed. HHV values and experimental HHV values of biomass sources calculated using the equation were compared. Also, the absolute deviation and percent error values were calculated. In addition, the success of the equation was compared with 17 different model equations in the literature. It has been determined that the success of the developed equation is higher than the other equations, the regression coefficient is 1 and the absolute deviation values are zero. In addition, the success of the developed equation in the estimation of calorific values of different biomass samples in the literature was investigated. At this stage, 18 different biomass sources were used and absolute deviation, percent error and regression coefficients of the equation were determined. These values are determined as $0.91 \mathrm{~kJ} / \mathrm{g}$ (max.), $4.3 \%$ (max.) and 0.91 , respectively. It is concluded that the developed equation gives very successful results as also for other biomass sources.
\end{abstract}

\section{GíRiş}

Bitkilerin ve canlı organizmaların kökeni olarak ortaya çıkan biyokütle, genelde güneş enerjisini fotosentez yardımıyla depolayan bitkisel organizmalar olarak düşünülse de, 100 yıllık periyottan daha kısa sürede yenilenebilen, karada ve suda yetişen bitkiler, hayvan atıkları, gübre, gıda endüstri atıkları, orman yan ürünleri ile kentsel atıkları da kapsayan organik maddelerin tümü biyokütle kapsamı içerisine girmektedir (Kırveli 2007, Gürleyik 2006, Dilek 2005, Taşar 2011). Fosil enerji kaynaklarına kıyasla biyokütle kaynakları çok daha düşük miktarda azot ve kükürt içerirler. $\mathrm{NO}_{x}$ emisyonları fosil yakıtlara göre yanma sıcaklığının düşük olması sebebiyle çok düşüktür (Gonzalez ve ark. 2004, Türe 2001). Bu nedenle yakma tesislerine yakın bölgelerdeki alanlarda asit yağmurlarına sebep olmazlar. Ayrıca yakılmaları ile atmosfere hiç net $\mathrm{CO}_{2}$ salınımı yapmadıkları için küresel ısınmaya yol açmazlar (Jenkins ve ark. 1998)

Biyokütle kaynaklarının biyo-enerji kaynağı olarak kullanılmasının çevresel avantajlarının yanı sıra bazı 
dezavantajları da vardır. Biyokütle kaynaklarının nem içerikleri genellikle yüksek olduğu için, ısıl değerleri oldukça düşüktür ve düşük çevrim verimine sahiptirler (Kırveli 2007, Lapuerta ve ark. 2004). Bu nedenle bir biyoyakıtın ticari değerinin tanımlanması, tesis verimliliğinin değerlendirilmesi ve dönüşüm süreci için teknikekonomik uygunluğunun ortaya konulması önem arz etmektedir. Yakma proseslerinde kullanılacak biyokütle kaynaklarının türü, fiziksel özellikleri (örn. Parçacık boyutu, yığın yoğunluğu, nem içeriği, kalorifik değer) ve kimyasal bileşimleri teknik ve ekonomik uygunluğu belirleyen parametrelerdir (Obernberger ve ark. 2006, Fernandez ve ark. 2008)

Artan biyoenerji talebi, mevcut biyokütle kaynaklarının enerji içeriğini (brüt kalorifik değer (GCV) veya üst ISI değer (ÜID)) değerlendirmek için teknolojilerin geliştirilmesine, daha fazla ihtiyaç duyulmasına sebep olmuştur. Bu ölçümler bir kalorimetrik bombada oksijen içinde yakılan katı bir biyo-yakıtın birim kütlesi için joule cinsinden özgül yanma enerjisinin mutlak değerinin tespit edilmesi şeklinde uygulanmaktadır. Ancak kalori tayini kurulum, ölçüm ve hesaplama prosedürleri gerektiren zaman alıcı ve karmaşık bir süreçtir. Kalorimetrik verilerin yokluğunda, ya da ölçümün mümkün olmadığı şartlarda katı bir biyokütlenin ısıl değeri elementel, proximate ya da kimyasal bileşimi ile tahmin edilebilir (Meraza ve ark. 2002, Meraza ve ark. 2003). Yakıtların karakterizasyonu için yaygın olarak kullanılan bu analizler, kalori tayinine kıyasla daha kolay, hızlı ve ucuz bir şekilde yapılabilirler (Sheng ve Azevedo 2005).

Yakıtın üst ısı değerini ile elementel yada proximate analiz verilerini ilişkilendirmek için çok sayıda ampirik denklem geliştirilmiştir (Toscano ve Pedretti 2009, Gharagheız 2008, Frıedl ve ark. 2005, Thıpkhunthoda ve ark. 2005, Demırbas 1997, Erol ve ark. 2010, Demırbas 2001). Ancak, bunların çoğu fosil yakıtlar dikkate alınarak geliştirilmiştir ve biyokütle için geliştirilen korelasyonlar az sayıdadır (Parıkha ve ark. 2005, Channıwala ve Parıkh 2002, Boylu 2018). Biyokütle kaynakları üzerine yapılan sınırlı sayıdaki çalışmalarda, proximate analize dayalı korelasyonlar ile hesaplanan kalori değerlerinin, elementel analiz verilerine dayalı korelasyonlardan daha düşük doğruluğa sahip olduğunu vurgulanmıştır. Literatürde önerilen tüm korelasyonların regresyon katsayıları 0.85 'in altındadır. Ayrıca, birçok çalışmalarda, korelasyonları geliştirmek ve hesaplamak için kullanılan verilerin doğrudan yazar tarafından ölçülmediği, literatürden ve diğer kaynaklardan temin edildiği görülmektedir (Yin 2011). Bu durumda geliştirilen korelasyonların tahmin başarısını, hassasiyetini düşürmektedir.

Biyokütlenin proximate analizi (nem, kül, sabit karbon ve uçucu madde tayini) laboratuvar şartlarında kolaylıkla ve kısa sürede yapılabilen, özel bir cihaz, ekipman yada kimyasal gerektirmeyen ucuz ve kolay yöntemdir. Biyokütlenin proximate analiz verilerinden üst değerini hesaplayabilecek başarısı yüksek model eşitlikler geliştirilebilmesi durumunda, farklı atık biyokütle türlerinden karışım yapılarak, termal dönüşüm süreçlerine uygun kombine hammaddeler hazırlanabilmesi ya da yakma prosesleri için Isı verimi yüksek karışımlar oluşturulabilmesi mümkün olabilecektir. Türkiye'nin mevsimsel olarak değişiklik gösteren tarımsal ve ormansal atık türü çeşitliliği ve rezervleri düşünüldüğünde, atıkların verimli ve sürdürülebilir olarak birlikte değerlendirilmesinin önünün açılacağı düşünülmektedir.

Bu amaçla bu çalışmada, mevcut laboratuvar şartlarında, farklı tip biyokütle kaynaklarının ASTM standartlarına uygun olarak proximate analizleri ve kalori tayinleri gerçekleştirilmiştir. Elde edilen deneysel veriler MATLAB 2019A paket programı yardımı ile yapılan veri analizleri ile değerlendirilmiştir. Proximate analiz ve üst ISI değeri arasında yeni bir denklem (korelasyon-ampririk formül) geliştirilmiştir. Geliştirilen denklemin deneysel veriler ile uyumunu ortaya koymak için yüzde hata ve mutlak sapma değerleri hesaplanmış ve elde edilen sonuçlar literatür ile kıyaslanarak yorumlanmıştır. Ayrıca türetilen denkleminin uygulama başarısı ve hassasiyeti iki farklı şekilde sınanmıştır. İlk adımda, literatürde bulunan 17 farklı denklem deney veri grubuna uygulanmış elde edilen sonuçlar, türetilen denklemden elde edilen mutlak sapma ve yüzde hata değerleri ile karşılaştııılmıştır. íkinci adımda ise çalışmada geliştirilen denklem, literatürdeki mevcut farklı biyokütle kaynaklarının proximate analiz verilerine uygulanmış ve üst ısı değeri kestirimindeki başarısı ortaya konulmaya çalışıımıştır.

\section{MATERYAL VE METOT}

Çalışmada kullanılan atık biyokütle niteliği taşıyan çay posası, kayısı çekirdeği kabuğu, şeker pancarı küspesi, ceviz kabuğu, mobilya atık tozu, odun talaşları (kavak, çam, meşe, kayı) ve yerfıstığı kabuğu Elazığ'daki ticari işletmelerden toplanarak temin edilmiştir. Temin edilen biyokütle atıkları, laboratuvar koşullarında atmosferik şartlarda polietilen brandalar üzerinde ön kurutma işlemine tabi tutulduktan sonra, $80^{\circ} \mathrm{C}^{\prime}$ de 48 saat süre ile etüvde kurutulmuştur. Deneysel çalışmalarda 
kullanılmadan önce, kurutulan atık biyokütle örnekleri gıda öğütücüsü (Renas marka) kullanılarak öğütülmüş ve laboratuvar ölçekli vibrasyonlu bir elek serisi kullanılarak fraksiyonlarına ayrılmıştır.

\subsection{Biyokütle Kaynaklarının Proximate Analizi}

Atık biyokütle örneklerinin elek analizleri sonucu elde edilen $154 \mu \mathrm{m}$ (100 mesh elek altı) parçacık boyutundaki fraksiyonu proximate analiz sürecinde kullanılmıştır. Yapılan tüm analizler, 3 paralel örnekle gerçekleştirildi ve paralel çalışmaların sonuçları dikkate alınarak ortalama değerler hesaplanmış ve sunulmuştur.

Nem tayini: Deneysel çalışmalarda kullanılan atık örneklerinin öncelikle nem tayini yapılmıştır. Nem tayini, Mettler U16 nem tayin cihazı kullanılarak, numunelerin $80{ }^{\circ} \mathrm{C}$ sıcaklıkta sabit tartıma getirilmesi ile gerçekleştirilmiştir. Örneklerin yüzde nem içeriği (\%M) cihazdan okunmuştur.

Uçucu madde miktarı tayini: Uçucu madde tayini ASTM E 872 (1982) standardına göre gerçekleştirilmiştir. Sabit tartıma getirilen kroze içine, $1 \pm 0.001 \mathrm{~g}\left(\mathrm{~g}_{1}\right)$ atık biyokütle numunesi konulmuştur. Krozenin kapağı kapatılarak $900 \pm 50{ }^{\circ} \mathrm{C}^{\prime}$ deki kül fırına yerleştirilmiştir. Kroze fırında tam olarak $7 \mathrm{dk}$. bekletildikten sonra, fırından çıkarılmış ve desikatörde soğutularak son tartımı $\left(g_{2}\right)$ alınmıştır. Ağılık kaybından uçucu madde miktarı tespit edilmiştir. Örneklerdeki uçucu madde miktarı, Eşitlik 1 yardımıyla hesaplanmıştır.

Uçucu Madde yüzdesi (\% UM) $=\frac{g_{1}-g_{2}}{g_{1}} x 100-M$

Burada;

$\mathrm{g}_{1}=$ Biyokütle örneklerinin ilk ağırlığı (g),

$\mathrm{g}_{2}=$ Örneklerin analiz sonrasında ölçülen ağırlı̆ı (g),

$M=B e l i r l e n e n$ nem yüzdesini ifade etmektedir.

Kül miktarı tayini: Örneklerin kül içeriği ASTM E 1755 (1995) standardına göre belirlenmiştir. Uçucu madde analizi sonrasında geriye kalan karbon içeriği yüksek örneği içeren kroze, ağzı açık olarak $600 \pm 50{ }^{\circ} \mathrm{C}^{\prime}$ ye ısıtılan fırında tutularak örnekle birlikte sabit tartıma getirilmiştir ve kroze ağırlığından yararlanılarak kalan külün miktarı tespit edilmiştir $\left(\mathrm{g}_{1}\right)$.

Kül yüzdesi $(\% K)=\frac{g_{1}}{g_{2}} x 100$

Bu eşitlikte;

$\mathrm{g}_{1}=$ Kül ağırlığı (g),

$\mathrm{g}_{2}=$ Kullanılan biyokütle numunesinin ağırlığıdır (g).

Sabit karbon tayini: Biyokütle atıklarının içerdiği sabit karbon miktarı aşağıdaki eşitlik kullanılarak, farktan hesaplanmıştır.

$\%$ Sabit Karbon $=100-(\%$ UM+ \% M + \% K $)$

\subsection{Biyokütle Kaynaklarının Isıl Değerlerin Belirlenmesi}

Biyokütle atıklarının ısıl değerleri, Elazığ Valiliği Çevre Ölçüm ve Analiz Laboratuvarında, Leco Ac-350 marka kalorimetre ile ASTM E870-82 (2006) standardına göre yapılmıştır.

\section{BULGULAR VE TARTIŞMA}

\subsection{Biyokütle Türlerinin Proximate Analizi Verileri ve ÜID Değerleri}

Çizelge 1 'de çalışmada kullanılan biyokütle örneklerinin proximate bileşimleri ve üst ISI değerleri (ÜID) sunulmuştur. Bu tablodaki UM, K ve SC kısaltmaları, sırasıyla uçucu maddeleri, kül ve sabit karbon içeriklerini göstermektedir. Proximate analiz prosedürüne göre, nem, uçucu madde ve kül içerikleri deneysel olarak belirlenmiş, sabit karbon içeriği ise nem, uçucu madde ve kül içeriğinin toplamının 100'den çıkarılmasıyla hesaplanmıştır. Ancak Çizelge 1'de sunulan UM, SC ve kül içerikleri ayrıca nemsiz (kuru) temel üzerinden verilmiştir, çünkü biyokütle özelliklerinin karşılaştırılması bu şekilde çok daha anlamlı ve doğrudur. Bu nedenle nem içeriği Çizelge 1'de hariç tutulmuş, sunulmamıştır 
Çizelge 1. Biyokütle kaynaklarının proximate analiz sonuçları ve üst ısı değerleri (ÜID)

\begin{tabular}{|c|c|c|c|c|}
\hline \multirow{2}{*}{ Numune Adı } & \multirow{2}{*}{$\begin{array}{l}\text { Deneysel } \\
\text { ÜID (kj/g) }\end{array}$} & \multicolumn{3}{|c|}{ Proximate içerikleri ( $\%$ w) } \\
\hline & & SC (\%) & UM (\%) & K (\%) \\
\hline Çay Posası & 18.10 & 18.10 & 81.15 & 0.75 \\
\hline Kayısı Çekirdeği Kabuğu & 17.52 & 16.55 & 80.55 & 2.90 \\
\hline Şeker Pancarı Küspesi & 17.31 & 15.03 & 82.29 & 2.68 \\
\hline Ceviz Kabuğu & 17.85 & 18.67 & 78.40 & 2.93 \\
\hline Mobilya Fab. Atık Tozu & 18.23 & 19.21 & 79.78 & 1.01 \\
\hline Kavak Odun Talaşı & 17.23 & 13.89 & 84.06 & 2.05 \\
\hline Çam Odun Talaşı & 16.77 & 11.90 & 85.15 & 2.95 \\
\hline Meşe Odun Talaşı & 17.72 & 16.81 & 77.41 & 5.78 \\
\hline Kayın Odun Talaşı & 17.36 & 13.75 & 85.17 & 1.08 \\
\hline Yerfıstığı Kabuğu & 18.07 & 18.21 & 80.78 & 1.01 \\
\hline
\end{tabular}

Çizelge 1'de sunulan biyokütle örneklerinin proximate analiz verileri irdelendiğinde, numunelerin proximate analiz sonuçlarının çok geniş bir aralıkta değiştiğini görülmektedir. Uçucu madde içeriklerinin \% 85.15 ile \% 77.41 aralığında değiştiği ve bu oranın genel olarak yüksek olduğu göze çarpmaktadır. En yüksek uçucu madde içeriği çam odun talaşına aittir. Bu sonucun çam odun talaşının yüksek reçineli yapısından ve tipik bir odunsu lignoselülozik biyokütle kaynağı oluşundan kaynaklandığı düşünülmüştür. Biyokütle kaynaklarının kül içerikleri \%0.75 ile \%5.78 aralığında, sabit karbon içerikleri ise \%11.90 ile \%19.21 aralığındadır. Çay posasının kül içeriği, çam odun talaşının ise sabit karbon içeriği diğer biyokütle atıklarına kıyasla oldukça düşüktür. Çam odunu talaşının sabit karbon içeriğinin düşük olması, yakıt kalitesinin (üst ISI değerinin) diğer biyokütle örneklerine oranla düşük olması ile de uyum içerisindedir. Biyokütle örneklerinin proximate bileşimleri, literatürde mevcut lignoselülozik yapıya sahip olduğu bilinen diğer biyokütle örnekleri ile karşılaştırıldığında, karakteristik olarak benzer özellikler taşıdığı söylenebilir (Demirbaş 2004, Parikh ve ark. 2007, Demirbaş 1997, Parikh ve ark. 2005, Demirbaş 2003, Naik ve ark. 2010, Telmo ve ark. 2010, Khan ve ark. 2009, Demirbaş 2005).

Biyokütlenin yakıt değeri, büyük ölçüde üst ısı değeri ile ilişkilidir. Yakıt olarak kullanılacak biyokütle kaynaklarının birbiri ile karşılaştırmak için genellikle üst Isı değerleri kullanılmaktadır. Biyokütle kaynaklarının proximate içerikleri yakma prosesini doğrudan etkileyen önemli parametrelerdir. Yüksek kül içeriğine sahip biyokütle kaynakları yakıt olarak daha az arzu edilirken, yüksek sabit karbon içeriğine sahip biyokütle kaynakları daha fazla tercih edilmektedir. Çünkü biyokütle kaynaklarının kül içeriği (inorganik madde içerikleri), yanma prosesi esnasında, oksijen difüzyonunu azaltmakta ve yanma verimini düşürmektedir (García ve ark. 2014, Demirbas 2002).
Çizelge 1 incelendiğinde çalışmada kullanılan biyokütle örneklerinin üst ISı değerleri irdelendiğinde en düşük ÜID’nin çam odun talaşı için $16.77 \mathrm{~kJ} / \mathrm{g}$ ve en yüksek ÜID ise mobilya fabrikası atık tozu için $18.23 \mathrm{~kJ} / \mathrm{g}$ olarak ölçüldüğü görülmektedir. Elde edilen üst ısı değerlerinin, biyokütle kaynaklarının sabit karbon içerikleri ile doğru orantılı olarak değişim gösterdiği göze çarpmaktadır.

Biyokütle kaynaklarının proximate analiz verileri ile üst ısı değerlerini ilişkilendirmek için MALTLAB 2019A programı kullanılarak matematiksel denklem geliştirilmiştir ve Çizelge 2' de “*” denklemi olarak sunulmuştur.

Ayrıca, Çizelge 2'de literatürde proximate analiz verilerinden biyokütle kaynaklarının ÜID’nin hesaplanmasında kullanılan diğer denklemlerde yer almaktadır. Çizelge 2'de verilen denklemler doğrusal ve doğrusal olmayan terimler içermektedir. Bu çalışmada geliştirilen denklem (* denklemi) sadece doğrusal terimler içerirken, 6-9 denklemleri doğrusal olmayan terimler de içermektedir. Ayrıca Çizelge 2'de sunulan eşitlik 10 ve 12 'nin çalışmamızda türetilen denkleme katsayısal büyüklük (UM ve SC terimlerine ait katsayıların) olarak oldukça yakın olduğu göze çarpmaktadır.

Literatürde mevcut, farklı çalışmalarda geliştirilen model eşitliklerin, proximate analiz değişkenlerinin üst ısı değeri üzerine etkilerini farklı şekillerde dikkate aldığı göze çarpmaktadır. Eşitlik 1-5 ve 12, UM, SC ve kül içeriğinin üst ISI değeri üzerine ortak etkisi olduğunu ortaya koyarken, diğer denklemler en fazla iki bağımsız değişkenin etkisini içermektedir. Öte yandan eşitlik 5 ila 8 arasındaki denklemlerin, UM veya SC'nun ters etkilerini de ortaya koyduğu, hem doğrusal hem de doğrusal olmayan parametreler içerdiği fark edilmektedir. 
Çizelge 2. MATLAB 2019A programı ile elde edilen denklem ve literatürde mevcut denklemler

\begin{tabular}{|c|c|c|c|c|}
\hline \multicolumn{2}{|c|}{ ìlişki kurulan değişkenler } & \multirow{2}{*}{ No } & \multirow{2}{*}{ Model Eşitlikler } & \multirow{2}{*}{ Referans } \\
\hline Bağımsız değişkenler & Bağımlı değişken & & & \\
\hline \multirow{18}{*}{$\begin{array}{c}\text { Sabit C (SC) } \\
\text { Uçucu Madde (UM) } \\
\text { Kül (K) }\end{array}$} & \multirow{18}{*}{ Üst ISI değeri (ÜID) } & $*$ & Ü $I D=0.312 S C+0.1534 U M$ & \multirow{9}{*}{ Özyuğuran ve Yaman 2017} \\
\hline & & 1 & Ü $I D=167.2-1.449 U M-1.562 S C-1.846 \mathrm{~K}$ & \\
\hline & & 2 & Ü $I D=-17.507+0.3985 U M+0.2875 S C$ & \\
\hline & & 3 & Ü $I D=22.3418-0.1136 S C-0.3983 K$ & \\
\hline & & 4 & Ü $I D=10.982+0.1136 U M-0.2848 K$ & \\
\hline & & 5 & $U I D=-18.37-0,8469 S C-1,1251 K+4420 / U M$ & \\
\hline & & 6 & $U I D=44.336+0.286 S C-2394.7 / U M$ & \\
\hline & & 7 & $U I D=28.296-0.2887 K-656.2 / U M$ & \\
\hline & & 8 & $U I D=18.297-0.4128 K+35.8 / S C$ & \\
\hline & & 9 & $U I D=-10.81408+0.3133(U M+S C)$ & Jiménez ve Gonzalez 1991 \\
\hline & & 10 & $U I D=0.1708 U M+0.3543 S C$ & Cordero ve ark. 2001 \\
\hline & & 11 & $U I D=-3.0368+0.2218 U M+0.2601 S C$ & Sheng ve Azevedo 2005 \\
\hline & & 12 & $U I D=0.1559 U M+0.3536 S C-0.0078 K$ & Parikh ve ark. 2005 \\
\hline & & 13 & Ü $I D=20.086-0.261 K$ & Callejón ve ark 2014 \\
\hline & & 14 & $U I D=0.1905 U M+0.2521 S C$ & Yin ve ark. 2011 \\
\hline & & 15 & ÜID $=-13.173+0.416 U M$ & \multirow[b]{2}{*}{ Callejón ve ark. 2014} \\
\hline & & 16 & ÜID $=-2.057-0.092 K+0.279 U M$ & \\
\hline & & 17 & ÜID $=0.1905 U M+0.2521 S K$ & García ve ark. 2014 \\
\hline
\end{tabular}

$\mathrm{Bu}$ çalışmada geliştirilen model eşitlik incelendiğinde $(U I D=0.312 \times S C+0.1534 x U M+0 \times k u ̈ l), \quad$ ÜID'nin uçucu madde ve sabit karbon içeriklerinin bir fonksiyonu olduğu ancak, kül içeriğinin bir fonksiyonu olmadığı (katsayısının 0 olduğu için) görülmektedir. Büyokütlenin ÜID’nin tahmini değerinin hesaplaması için kül analizine gerek duyulmayacağı sonucuna varılmıştır. Ayrıca, geliştirilen eşitlikten, biyokütle örneklerini uçucu madde ve sabit karbon içeriği arttıkça üst ısı değerlerinin artış göstereceği anlaşılmaktadır. Yüksek uçucu madde içeriği, düşük sıcaklıklarda yüksek reaktiviteye sebep olan, ateşlemeyi kolaylaştıran bileşen olarak bilinse de, bağımsız değişkenlerin katsayıları irdelendiğinde, ÜID üzerine sabit karbon içeriğinin, uçucu madde içeriğine kıyasla iki kat daha fazla etki ettiği anlaşılmaktadır.

Proximate analiz verileriyle üst Isı değerleri arasındaki ilişkiyi ifade eden, bu çalışmada türetilen model eşitlik yardımı ile hesaplanan teorik üst ısı değerleri Çizelge 3'de özetlenmiştir. Türetilen eşitlikle hesaplanan ÜID, deneysel ÜID verileriyle birebir uygunluk içerisinde olup, mutlak sapma ve yüzde hata değeri içermemektedir. Bu yüzden Çizelge 3'de mutlak sapma ve yüzde hata değerleri için "_" kullanılmıştır. Çizelge 3 incelendiğinde, hesaplanan en yüksek ÜID (18.23 kJ/g) değerinin mobilya fabrikası atık tozuna ait olduğu ve deneysel ölçümle birebir eşit olduğu görülmektedir. Bu durum mobilya üretim esnasında kullanılan yapıştırıcı vb. katkı maddelerinden kaynaklanmaktadır. Diğer taraftan en düşük üst ısı değeri (\%16.77), uçucu madde içeriği yüksek olsa da, sabit karbon içeriği diğer bileşenlere kıyasla daha düşük olan çam odun talaşında elde edildi ve bu değer, deneysel üst ısı değeri ile birebir uyum içerisindedir. Atık biyokütle örnekleri için deneysel ve hesaplanan ÜID’nin, aynı tabloda karşılaştırmalı olarak verilmiş literatürdeki çalışmalarda elde edilen ÜID veriler ile uygunluk gösterdiği tespit edilmiştir. Yer fıstığı kabuğu, meşe odun talaşı, kayısı çekirdeği kabuğu ve ceviz kabuğunun ÜID’nin diğer atık türlerine kıyasla literatürde sunulan ÜID verilerine oldukça yakın olması, bu atıkların kimyasal bileşimlerinin yetiştirildiği bölge, iklim şartları, toprak türü ve bileşimi gibi parametrelerden daha az etkilendiği şeklinde yorumlanmıştır. 
Çizelge 3. Biyokütle kaynaklarının proximate analiz verilerinden türetilen denklem yardımı ile hesaplanan teorik üst ıSı değerleri ve literatürle kıyaslanması

\begin{tabular}{lcccccc}
\hline Biyokütle türü & $\begin{array}{c}\text { Deneysel ÜıD } \\
\mathbf{( k j / g )}\end{array}$ & $\begin{array}{c}\text { Teorik ÜID } \\
\mathbf{( k j / g )}\end{array}$ & $\begin{array}{c}\text { Mutlak } \\
\text { Sapma }\end{array}$ & $\begin{array}{c}\text { Yüzde } \\
\text { Hata }\end{array}$ & $\begin{array}{c}\text { Literatürde } \\
\text { verilen } \\
\text { ÜID (kj/g) }\end{array}$ & Referans \\
\hline Çay posası & 18.10 & 18.10 & - & - & 17.10 & Caglar 2009 \\
Kayısı ç. kabuğu & 17.52 & 17.52 & - & - & 17.70 & Duranay ve Yılgın 2018 \\
Şeker p. küspesi & 17.31 & 17.31 & - & - & 18.12 & Adiletta ve ark.2020 \\
Ceviz kabuğu & 17.85 & 17.85 & - & - & 17.91 & Goutam ve ark.2019 \\
Mobilya A. Tozu & 18.23 & 18.23 & - & - & $\sim 20.0$ & Plis ve ark.2016 \\
Kavak & 17.23 & 17.23 & - & - & 18.67 & Gómez ve ark. 2020 \\
Çam & 16.77 & 16.77 & - & - & 20.35 & Duranay ve Yılgın 2018 \\
Meşe & 17.72 & 17.72 & - & - & 17.65 & Demirbas 2017 \\
Kayın & 17.36 & 17.36 & - & - & 19.20 & Perea ve ark. 2018 \\
Yerfıstığı kabuğu & 18.07 & 18.07 & - & - & 18.54 \\
\hline
\end{tabular}

Şekil 1' de bu çalışmada geliştirilen model eşitlik kullanılarak hesaplanan ÜID ile deneysel ÜID arasındaki ilişkiyi ifade eden grafik incelendiğinde Regresyon katsayısının 1 olduğu, yani standart sapma ve mutlak hatanın söz konusu olmadığı, elde edilen model eşitliğin deneysel veriler ile tam uyumlu olduğu kanıtlanmıştır.

Literatürde önerilen ve bu çalışmadaki deneysel verilere uygulanan tüm eşitliklerin (Eşitlik 1-17) regresyon katsayılarının, bu çalışmada geliştirilen eşitliğin regresyon katsayısının altında olduğu da (Şekil 1'deki diğer grafiklerden) görülmektedir. Bu sebeple, MATLAB 2019A programı ile yapılan veri analizi sonucu geliştirilen model eşitliğin biyokütle örneklerinin proximate analiz verilerinden ÜID'nin hesaplanabilmesi için oldukça başarılı olduğu sonucuna varılmıştır.

Şekil 1'de, Çizelge 2 sunulan literatürden alınan denklemler kullanılarak hesaplanan ÜID ile deneysel ÜID arasındaki ilişki ve regresyon katsayıları görülmektedir. Denklemlerin regresyon katsayısı değerlerinin birbirinden oldukça farklı olduğu, 0.001 ile 0.99 gibi oldukça geniş bir aralıkta değiştiği tespit edilmiştir. Eşitlik 10-11-12-14-15 ve $18^{\prime}$ in regresyon katsayısının $0.6^{\prime}$ nın üzerinde olduğu görülmektedir. Geliştirilen denkleme katsayı oranı olarak benzerliği olan Eşitlik 10 ve 12 'nin deneysel verilere uyumunun da diğer denklemlerden çok daha iyi olduğu, regresyon katsayılarının sırası ile 0.999 ve 0.998 olduğu belirlenmiştir. Benzer şekilde, bu iki denklem kullanılarak hesaplanan ÜID'lerinin mutlak sapmalarının 0.68-2.20 $\mathrm{kJ} / \mathrm{g}$ arasında değiştiği hesaplanmıştır.

Geliştirilen denklemin başarısı, ikinci adımda literatürde sunulan farklı biyokütle örneklerinin proximate ve kalori analiz sonuçları kullanılarak sınanmıştır. Elde edilen sonuçlar Çizelge 4'de sunulmuştur. Denklem kullanılarak hesaplanan ÜID ile literatürden temin edilen ÜID arasındaki ilişki ise Şekil 2'de görülmektedir. Geliştirilen denklemin literatür verilerine uygulanması durumunda da başarısı oldukça yüksek bulunmuştur. Regresyon katsayısı 0.90'nın üzerindedir ve yüzde hata değeri maksimum \% 4.3'dür. Mutlak sapma değeri ise 0.02-0.91 $\mathrm{kJ} / \mathrm{g}$ aralığında değişmektedir. 

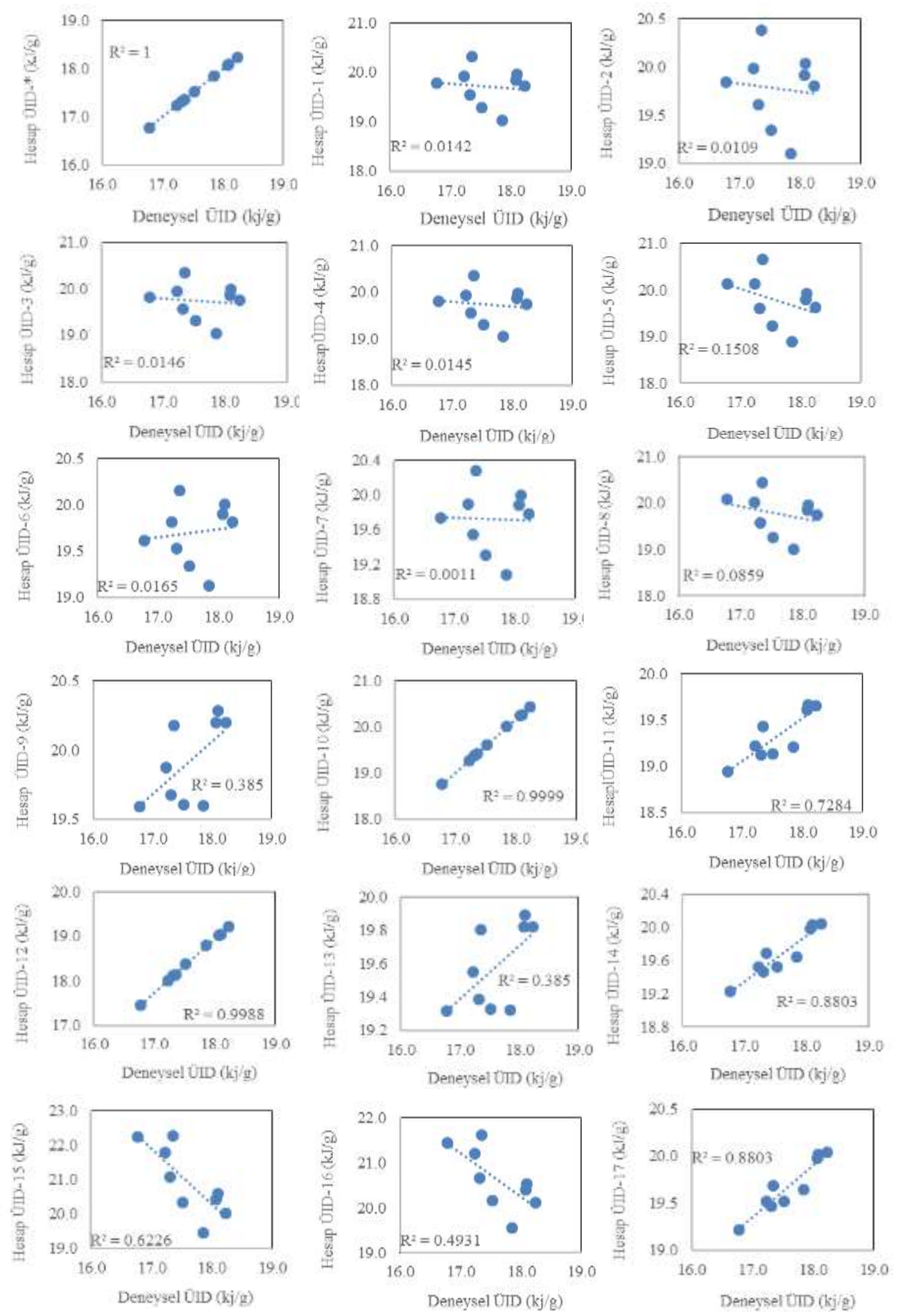

Şekil 1.Deneysel ÜID ile model denklemler kullanılarak hesaplanan ÜID değeri arasındaki ilişkiler 
Çizelge 4. Geliştirilen denklemin literatürdeki biyokütle kaynaklarına uygulanması

\begin{tabular}{|c|c|c|c|c|c|c|c|c|}
\hline Biyokütle Türleri & $\begin{array}{c}\text { Sabit C } \\
(\%)\end{array}$ & $\begin{array}{c}\text { Uçucu } \\
\text { Madde } \\
(\%)\end{array}$ & $\begin{array}{l}\text { Kül } \\
\text { (\%) }\end{array}$ & $\begin{array}{l}\text { ÜID } \\
k J / g\end{array}$ & $\begin{array}{c}\text { Hesaplanan } \\
\text { ÜID } \\
\text { kj/g }\end{array}$ & $\begin{array}{c}\text { Mutlak } \\
\text { Hata }\end{array}$ & $\begin{array}{c}\% \\
\text { Hata }\end{array}$ & Referans \\
\hline Ladin Gövde Talaşı & 28.50 & 70.70 & 0.80 & 19.92 & 19.74 & 0.18 & 0.92 & \multirow{5}{*}{$\begin{array}{c}\text { Demirbas } \\
2002\end{array}$} \\
\hline Kayın Gövde Talaşı & 24.80 & 74.40 & 0.80 & 19.33 & 19.15 & 0.18 & 0.93 & \\
\hline Ailanthus Gövde Talaşı & 24.90 & 74.50 & 0.60 & 19.43 & 19.20 & 0.23 & 1.20 & \\
\hline Ayçiçeği Kabuğu & 21.50 & 78.00 & 0.50 & 18.75 & 18.67 & 0.08 & 0.41 & \\
\hline Fındık Kabuğu & 28.30 & 70.30 & 1.40 & 20.49 & 19.61 & 0.88 & 4.28 & \\
\hline Şeftali Küspesi & 23.34 & 71.21 & 5.44 & 18.23 & 18.21 & 0.02 & 0.13 & \multirow{10}{*}{ Özyuğuran ve Yaman 2017} \\
\hline Kakao Kabuğu & 20.56 & 75.03 & 4.41 & 17.85 & 17.92 & 0.07 & 0.42 & \\
\hline Fıstık Kabuğu & 20.53 & 79.32 & 0.15 & 19.16 & 18.57 & 0.59 & 3.06 & \\
\hline Keçiboynuzu & 24.16 & 70.29 & 5.54 & 18.04 & 18.32 & 0.28 & 1.55 & \\
\hline Ayçiçeği Sapı & 13.81 & 75.09 & 11.1 & 16.18 & 15.83 & 0.35 & 2.18 & \\
\hline Kırmızı Mercimek Kabuğu & 20.03 & 74.73 & 5.24 & 18.27 & 17.71 & 0.56 & 3.05 & \\
\hline Mısır Kabuğu & 16.02 & 76.79 & 7.19 & 16.55 & 16.78 & 0.23 & 1.38 & \\
\hline Tütün Atığı & 11.78 & 72.85 & 15.4 & 14.51 & 14.85 & 0.34 & 2.35 & \\
\hline Bakla Kabuğu & 17.33 & 74.97 & 7.70 & 16.24 & 16.91 & 0.67 & 4.11 & \\
\hline Kayısı Küspesi & 20.12 & 78.80 & 1.08 & 18.52 & 18.37 & 0.15 & 0.83 & \\
\hline Ceviz Kabuğu & 71.52 & 19.33 & 1.65 & 17.91 & 17.00 & 0.91 & 5.07 & Plis ve ark. 2016 \\
\hline Kavak Odun Talaşı & 81.00 & 18.13 & 0.87 & 18.67 & 18.08 & 0.59 & 3.15 & Demirbas 2017 \\
\hline Şeker Pancarı Küspesi & 79.00 & 16.94 & 4.24 & 18.12 & 17.40 & 0.72 & 3.95 & Goutam ve ark. 2019 \\
\hline
\end{tabular}

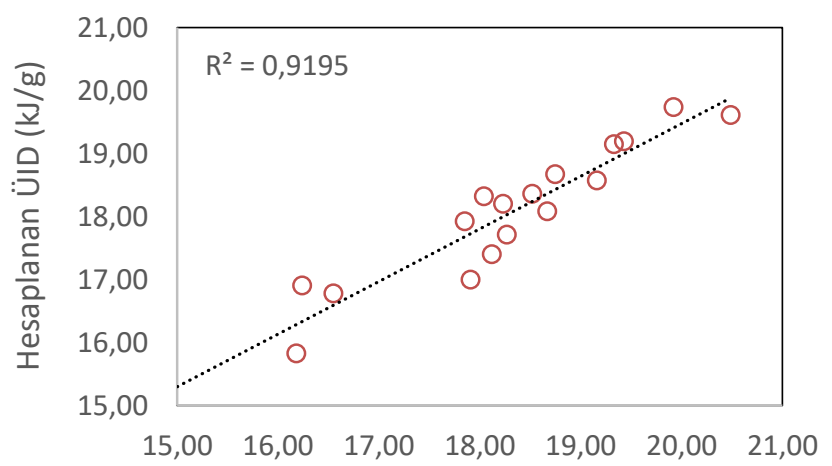

Deneysel ÜID (kj/g)

Şekil 2. Geliştirilen denklemin literatürdeki biyokütle kaynaklarına uygulanma başarısı

\section{SONUÇ}

Biyo-enerji sistemlerinin analiz ve dizayn edilebilmesi için biyokütle kaynaklarının ısıl değerlerinin bilinmesi önem arz etmektedir. Bu nedenle, yenilenebilir enerji kaynaklarının önemli bir grubunu oluşturan biyokütle enerji kaynaklarının yakıt özelliklerini karşılaştırması amacı ile proximate bileşimlerinin kullanılabileceği ön görüsü ile çalışma gerçekleştirilmiştir.

Bu çalışmada, atık niteliği taşıyan ligoselülozik yapılı biyokütle kaynaklarının proximate analiz verileri ile üst ısı değerleri arasında ilişki kurulmuş, proximate analiz verilerini kullanarak geliştirilen denklem yardımı ile üst ısı değerinin oldukça yüksek bir başarı ile hesaplanabileceği ortaya konulmuştur. Deneysel ÜID ile çalışmada geliştirilen denklem kullanılarak hesaplanan teorik ÜID'nin birebir aynı olduğu, yüzde hata değerinin 0 , regresyon katsayısının 1 olduğu tespit edilmiştir.

Model eşitliğin literatürdeki proximate analiz verilerine uygulanması ile elde edilen başarının da oldukça yüksek olduğu, regresyon katsayısının 0.90'ın üstünde, yüzde hata değerinin ise \% 4.5'in altında olduğu belirlenmiştir. Geliştirilen denklem ile tatmin edici bir şekilde biyokütle kaynaklarının ÜID tahminlerinin yapılabileceği, kalorifik analize gerek duyulmayacağı anlaşılmıştır. 
Literatürde mevcut model eşitlikler ile bu çalışmada geliştirilen denklem kıyaslanması amacı ile yapılan regresyon analizi sonucunda, geliştirilen denklemin diğer model eşitliklere kıyasla daha başarılı olduğu görülmüştür.

Sonuç olarak, geliştirilen model eşitlik kullanılarak, farklı bileşime ve enerjitik verime sahip atık türlerinin birlikte değerlendirilebileceği anlaşılmıştır. Enerji üretim prosesine uygun olarak istenilen ÜID'ne sahip karışımların oluşturulabileceği sonucuna varılmıştır. Geliştirilen denklem sayesinde, Türkiye'nin sezonluk olarak ortaya çıkan biyokütle atıklarının ekonomik bir katma değer yaratacağı ön görülmektedir. Bu atıkların özellikle yakma proseslerinde verimli ve sürdürülebilir bir şekilde hammadde olarak kullanılabilmesinin önü açılmıştır.

\section{Kaynaklar}

Adiletta G, Brachi P, Riianova E, Crescitelli A, Miccio M, Kostryukova N (2020). A Simplified Biorefinery Concept for the Valorization of Sugar Beet Pulp: Ecofriendly Isolation of Pectin as a Step Preceding Torrefaction. Waste and Biomass Valorization 11: 27212733.

ASTM-E 872 (1982). Volatile matter in the analysis of particulate wood fuels. Annual Book of ASTM Standards.

ASTM-E 1755 (1995). Ash in biomass. Annual Book of ASTM Standards. ASTM E870 - 82 (2006). Standard Test Methods for Analysis of Wood Fuels.

Boylu F, Karaağaçlıoğlu IE (2018). Evaluation of Coal Components-Coal Calorific Value Relationship. Yerbilimleri 39 (3):221-236.

Caglar A (2009). Valorization of tea wastes by pyrolysis. Energy Education Science and Technology Part A: Energy Science and Research 23(2):135-144.

Callejón-Ferre AJ, Carreño-Sánchez J, SuárezMedina FJ, Pérez-Alonso J, Velázquez-Martí B (2014). Prediction models for higher heating value based on the structural analysis of the biomass of plant remains from the greenhouses of Almería (Spain). Fuel 116: 377387.

Channıwala SA, Parıkh PP (2002). A unified correlation for estimating HHV of solid, liqüID and gaseous fuel. Fuel 81:1051-1063.

Cordero T, Marquez F, Rodriguez-Mirasol J, and Rodriguez J (2001). Predicting heating values of lignocellulosic and carbonaceous materials from proximate analysis. Fuel 80:1567-1571.

Demirbas A (2002). Relationships Between Heating Value and Lignin, Moisture, Ash and Extractive Contents of Biomass Fuels. Energy Exploratıon \& Exploıtatıon 20(1):105-111.

Demırbas A (2001). Relationships between lignin contents and heating values of biomass. Energy Conversion \& Management 42: 183-188.

Demırbas A 1997). Calculation of higher heating values of biomass fuels. Fuel 76: 431-434.

Demirbas A (2004). Combustion characteristics of different biomass fuels. Prog Energy Combust Sci 30: 219-30.

Demirbaş A (2003). Sustainable cofiring of biomass with coal. Energy Convers Manag 44: 1465-1479.

Demirbas A (2017). Higher heating values of lignin types from wood and non-wood lignocellulosic biomasses. Energy Sources, Part A: Recovery, Utılızatıon, and Environmental Effects 39(6):592-598.
Demirbas A (2005). Potential applications of renewable energy sources, biomass combustion problems in boiler power systems and combustion related environmental issues. Prog Energy Combust Sci 31:171-192.

Dilek A (2005). Aspir (Charthamus Tinctorius L.) Tohumu Pres Küspesinin Alternatif Enerji Kaynagı Olarak Değerlendirilmesi, Doktora tezi, Osmangazi Üniversitesi, Fen Bilimleri Enstitüsü.

Duranay N, Yılgın M (2018). Kısa Analiz Verileri Kullanılarak Biyokütlenin Üst Isı Değerinin Hesaplanması. Academic Platform Journal of Engineering and Science 6-2:103-108.

Erol M, Haykiri-Acma H, Kucukbayrak S (2010). Calorific value estimation of biomass from their proximate analyses data. Renewable Energy 35:170-73.

Fernandez Lorente MJ, Carrasco Garcla JE (2008). Suitability of thermo-chemical corrections for determining gross calorific value in biomass. Thermochimica Acta 468:101-107.

Friedl A, PadouvaS E, Rotter H, Varmuza K (2005). Prediction of heating values of biomass fuel from elemental composition. Analytica Chimica Acta 544:191-198.

García R, Pizarro C, Lavín AG, Bueno JL (2014). Spanish biofuels heating value estimation. Part II: Proximate analysis Data. Fuel 117:11391147.

Gharagheız F (2008). A simple equation for prediction of net heat of combustion of pure chemicals. Chemometrics and Intelligent Laboratory Systems 91:177-180.

Gonzalez JF, Gonzalez-Garcıa C, Ramıro A, Gonzalez J, Sabıo E, Ganan $J$, Rodriguez M (2004). Combustion optimisation of biomass residue pellets for domestic heating with a mural boiler. Biomass \& Bioenergy 27/2:145-154.

Goutam SG, Monoj KG, Mondal K (2019). Slow pyrolysis of chemically treated walnut shell for valuable products: Effect of process parameters and in-depth product analysis. Energy 181:665-676.

Gómez-Martína JM, Castaño-Díaz M, Cámara-Obregón A, ÁlvarezÁlvarez P, Folgueras-Díaz MB, Diezc MA (2020).On the chemical composition and pyrolytic behavior of hybrid poplar energy crops from northern Spain. Energy Reports 6:764-76.

Gürleyik E (2006). Fosil Kaynakların Yağlı Tohumlar ile Birlikte Pirolizi ve Ürünlerin İncelenmesi, Yüksek Lisans Tezi, Anadolu Üniversitesi, Fen bilimleri Enstitüsü.

Jenkins BM, Baxter LL, Miles Jr TR, Miles TR (1998). Combustion properties of biomass. Fuel Processing Technology 54:17-46.

Jiménez L, and Gonzalez F. (1991). Study of physical and chemical properties of lignocellulosic residues with a view to the production of fuels. Fuel 70:947-950.

Khan A, De Jong W, Jansens P, Spliethoff H (2009). Biomass combustion in flülDized bed boilers: potential problems and remedies. Fuel Process Technol 90:21-50.

Kırveli Ş (2007). Biyokütle Enerji Kaynağı Olarak Pirinanın Doğrudan Yakılmasında Klinoptilolit Kullanımının Isıl Davranış ve Emisyon Değerlerine Etkilerinin İncelenmesi, Yüksek Lisans, Ege Üniversitesi, Tezi, Fen bilimleri Enstitüsü.

Lapuerta M, Hernandez JJ and Rodriguez J (2004). Kinetics of Devolatilization of Forestry Wastes From Thermogravimetric Analysis. Biomass and Bioenergy 27:385-391.

Meraza L, Oropeza M, Domınguez A (2002). Prediction of the Combustion Enthalpy of Municipal Solid Waste. Chem. Educator 7:66-70.

Meraza L, Domınguez A, Kornhauserb I, ROJas F (2003). A thermochemical concept-based equation to estimate waste combustion enthalpy from elemental composition. Fuel 82:14991507. 
Naik S, Goud VV, Rout PK, Jacobson K, Dalai AK (2010). Characterization of Canadian biomass for alternative renewable biofuel. Renew Energy 35:1624-1631.

Obernberger I, Brunner T, Barnthaler G (2006). Chemical properties of solid biofuels-significance and impact. Biomass and Bioenergy 30:973-982.

Özyuğuran A, Yaman S (2017). Prediction of Calorific Value of Biomass from Proximate Analysis. Energy Procedia 107:130 - 136.

Parikh J, Channiwala S, Ghosal G. (2007). A correlation for calculating elemental composition from proximate analysis of biomass materials. Fuel 86:1710-1719.

Parikh J, Channiwala SA and Ghosal GK (2005). A correlation for calculating HHV from proximate analysis of solid fuels. Fuel 84:487-494.

Perea-Moreno MA, Manzano-Agugliaro F, Hernandez-Escobedo $Q$, Perea-Moreno AJ (2018). Peanut Shell for Energy: Properties and Its Potential to Respect the Environment. Sustainability 10:3254.

Plis A, Kotyczka-Moran M, Kopczyn M, Labojko G (2016). Furniture wood waste as a potential renewable energy source: $A$ thermogravimetric and kinetic analysis. J Therm Anal Calorim DOI 10.1007/s10973-016-5611-7.

Sheng C, Azevedo JLT (2005). Estimating the higher heating value of biomass fuels from basic analysis data. Biomass and Bioenergy 28: 499-507.

Taşar Ş (2011). Mobilya Fabrikası Atık Tozunun Pirolizi. Fırat Üniversitesi, Fen Bilimleri Enstitüsü, Yüksek Lisans Tezi, Elazığ.

Telmo C, Lousada J, Moreira N (2010). Proximate analysis, backwards stepwise regression between gross calorific value, ultimate and chemical analysis of wood. Bioresour Technol 101:3808-3815.

Thipkhunthoda P, Meeyoob V, Rangsunvigita P, Kitıyanana B, Siemanonda K, Rırksomboon T (2005). Predicting the heating value of sewage sludges in Thailand from proximate and ultimate analyses. Fuel 84:849-857.

Toscano G, Pedretti EF (2009). Calorıfıc Value Determınatıon Ofsolıd Bıomass Fuelbysımplıfied Method. J. of Ag. Eng. - Riv. di Ing. Agr. 3:1-6.

Türe S (2001). Biyokütle Enerjisi, Tübitak Matbaası, Ankara.

Yin CY (2011). Prediction of higher heating values of biomass from proximate and ultimate analyses. Fuel 90:128-1132. 